\title{
Infrared Spectroscopic Study of Reaction of \\ Carbon Dioxide with Aqueous Amine Solutions
}

Chenhu Sun and Prabir K. Dutta*

Department of Chemistry and Biochemistry, The Ohio State University, Columbus, Ohio 43210, USA

"To whom correspondence should be addressed (dutta.1@osu.edu) 


\section{Supporting Information}

Calculation of absorptivity for $\mathrm{MEAH}^{+}$

Table S1. pH-dependent amine protonation equilibria. $\left([\mathrm{MEA}]_{\mathrm{TOTAL}}=[\mathrm{MEA}]+\right.$ $\left.\left[\mathrm{MEAH}^{+}\right]=4.91 \mathrm{M}\right)$

\begin{tabular}{|c|c|c|}
\hline $\mathbf{p H}$ & $[\mathbf{M E A}] \mathbf{( m o l} / \mathbf{L})$ & [MEAH $\left.\left.^{+}\right] \mathbf{( m o l} / \mathbf{L}\right)$ \\
\hline 11 & 4.85 & 0.06 \\
\hline 10 & 4.40 & 0.50 \\
\hline 9 & 2.28 & 2.62 \\
\hline 7.9 & 0.32 & 4.59 \\
\hline 6.2 & 0.01 & 4.90 \\
\hline
\end{tabular}

It is well known that the primary amine is involved in $\mathrm{pH}$-dependent protonation equilibria: $\mathrm{Am}+\mathrm{H}^{+} \stackrel{\mathrm{K}}{\leftrightarrow} \mathrm{AmH}^{+}$, where $\mathrm{K}$ is the equilibrium constant and $\mathrm{K}=\frac{\left[\mathrm{AmH}^{+}\right]}{[\mathrm{Am}]\left[\mathrm{H}^{+}\right]}$with a value of $\log \mathrm{K}=9.06$ for MEA. The standard MEA solution was titrated with concentrated $\mathrm{HCl}$ and the concentration of MEA and protonated MEA at different pH's was calculated and shown in in Table S1. IR spectra were also obtained on these samples.

The protonation of MEA results in the C-N stretching band shift from $1076 \mathrm{~cm}^{-1}$ to $1066 \mathrm{~cm}^{-1}$ (Figure S1), and these two peaks were deconvoluted. By using the absorbance value of fitted $\mathrm{MEAH}^{+}$peak at $1066 \mathrm{~cm}^{-1}$, the proportionality constant $\varepsilon$ at each $\mathrm{pH}$ was 
calculated, and the average for the five $\mathrm{pH}$ measurements led to $\varepsilon=0.012$ for $\mathrm{MEAH}^{+}$. This value was used to calculate the concentration of $\mathrm{MEAH}^{+}$produced in $\mathrm{CO}_{2}$ reaction. 


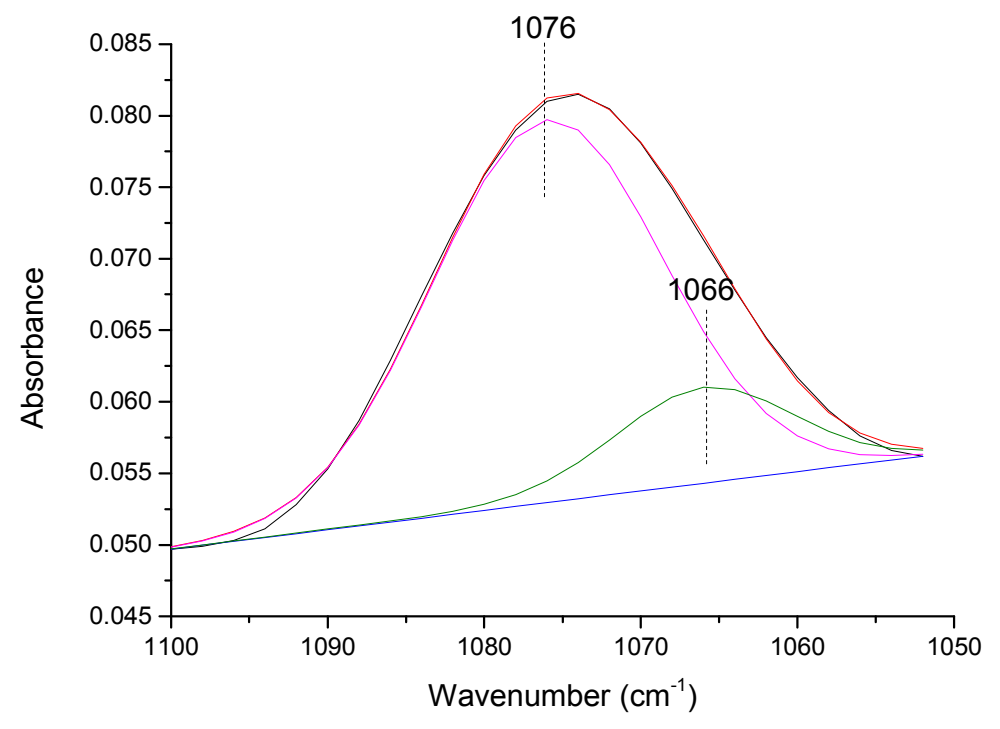

Figure S1. Peak fitting for $4.91 \mathrm{M}$ MEA in $15 \% \mathrm{CO}_{2} / 6 \% \mathrm{O}_{2}$ absorption for $5 \mathrm{~h}$ at $40{ }^{\circ} \mathrm{C}$. 
Calculation of absorptivity for MEA and methyl carbamate:

A series of standard solutions were prepared with pure MEA and methyl carbamate solutions. The absorbance at $1362 \mathrm{~cm}^{-1}$ and $1375 \mathrm{~cm}^{-1}$ was used for MEA and methyl carbamate, respectively to prepare a calibration curve. The points on the calibration curve yield a straight line (Beer's Law). The slope of that line provides a relationship between absorbance and concentration: $\mathrm{A}=\varepsilon \mathrm{C}$, where $\varepsilon$ is the proportionality constant. The Beer's Law graphs for two standard solutions are plotted in Figure S2, both of which show a linear relationship between absorbance and concentration. The proportionality constant $\varepsilon$ of MEA and methyl carbamate are acquired as 0.0018 and 0.0468, respectively. 

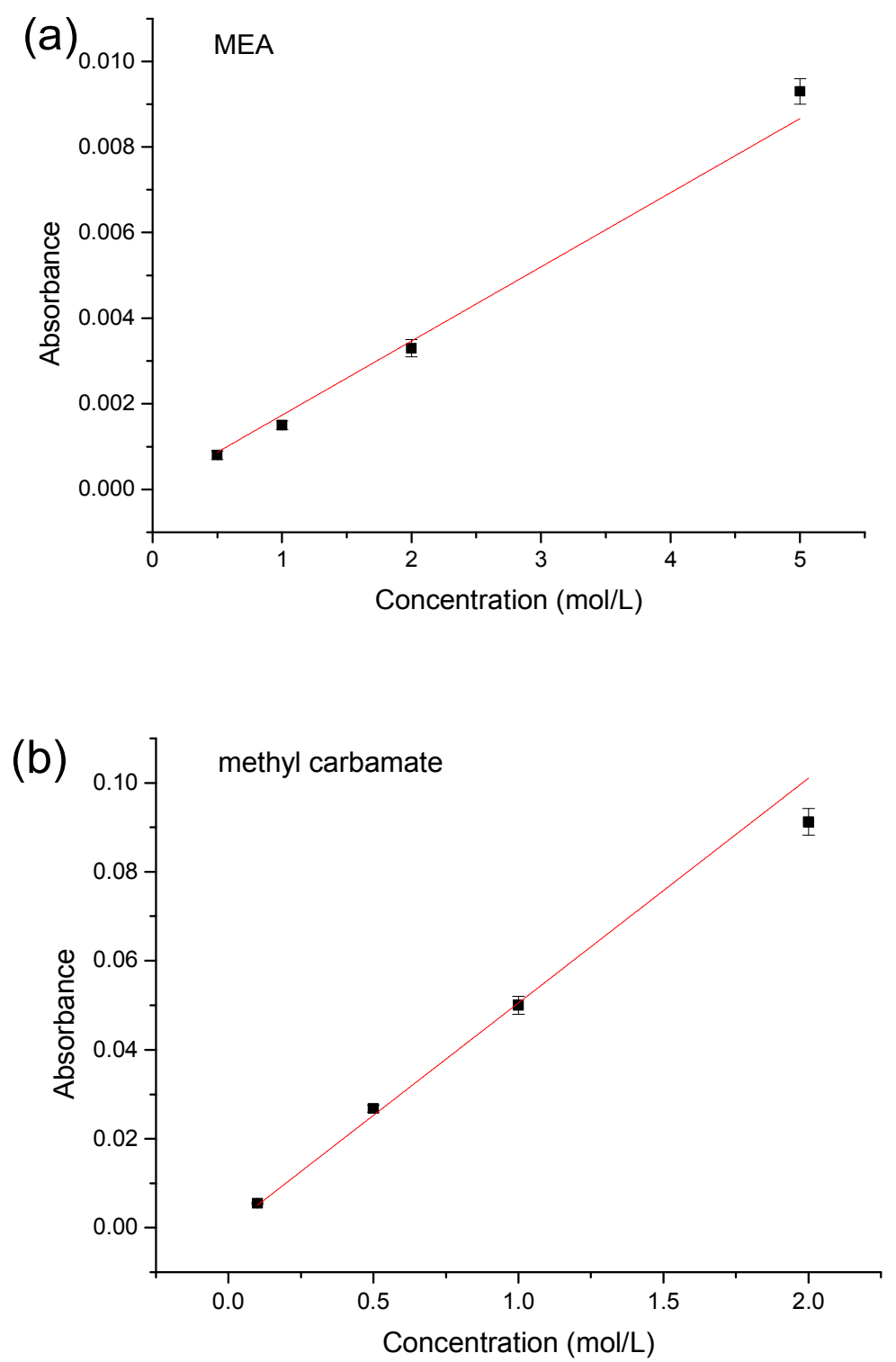

Figure S2. Beer's Law graphs of (a) MEA and (b) methyl carbamate. 


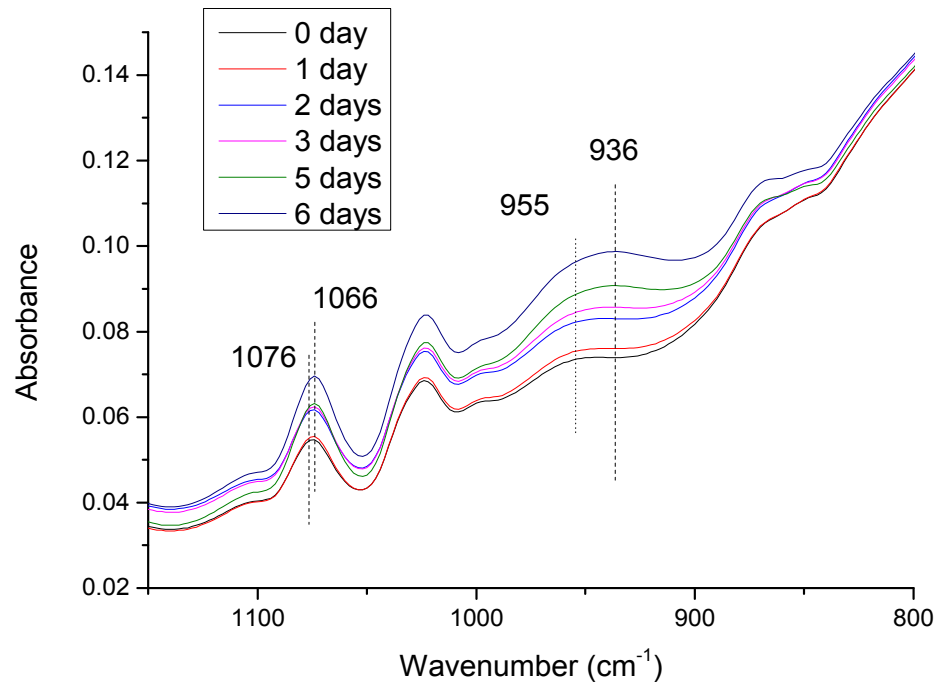

Figure S3. Evolution of FTIR absorbance spectra of $15 \mathrm{wt} \%$ MEA in $151 \mathrm{ppm} \mathrm{SO} / 6 \%$ $\mathrm{O}_{2}$ at $40{ }^{\circ} \mathrm{C}$. 